\title{
Annual Conference of the Museums Association.
}

THE fortieth annual conference of the Museums Association, held at Worthing on July 1-5, was in many respects the most successful in the history of that body. The success was due to many favouring circumstances. The Royal Commission on National Museums and the Miers Report on Provincial Museums had awakened the interest of a wider public; hints from the Commission that the national establishments might be helped to give more practical shape to their acknowledged sympathy with the local museums, as well as the bodily presence of two Carnegie Trustees with their secretary, roused the hopes of curators; the nearness to London enabled many busy people to attend and contribute papers; and, above all, the choice of Sir Henry Miers for president promised a practical address and a fruitful discussion.

A main object of the Association is to promote co-operation between museums of every kind. Sir Henry Miers took that as the subject of his address, and speakers had been chosen to approach it from various sides. Sir Henry has in mind a museum service for the whole country, parallel to the library service that has cast a net which now gathers in even small villages. As driving force for such a scheme he sees only the Museums Association. With small means the Association has already done much, but voluntary labour, manifesting its results only in the annual conference, the Museums Journal, and a few circulating collections, is no longer enough. A central office and a whole-time secretary are urgently needed, and to provide these more museums should come in. There is too much individualism and competition, too little co-operation and mutual aid between museums; the larger museums do not realise how much they stand to gain by helping their weaker brethren. Sir Henry indicated many openings for co-operation, among them the guidance of archæological excavation, the interchange of loan exhibits, and the training of curators.

In the ensuing discussion, Dr. Cyril Fox extended the idea of co-operation to the overseas members, and showed how ethnographical material stored in our museums might now be of more use if returned to the Dominions whence it came long ago ; he suggested a central clearing-house for archæological objects. The Earl of Crawford, comparing museums, picture-galleries, and libraries, pointed out that the public appreciation of museums called for greater mental effort; the three classes should be put on a level, since each is necessary for intellectual progress. Mr. A. J. K. Esdaile urged the need of a central office for arranging exchanges and exhibitions. Mr. Tate Regan thought that junior members of museum staffs should be welcomed to the Association at a smaller subscription but without the Journal. Dr. F. A. Bather replied that this would not help the juniors so long as their superiors did not encourage them to attend the Conference. As for a central clearing-house, the best course would be for each department of the national museums to receive and distribute its own class of material, but much could be done directly if use were made of the Journal. Other speakers advocated the extension of regional federations under the auspices of the Association.

The discussion was revived later by Dr. Hay Murray's suggestion that every large museum should adopt a small museum, and was carried further by Mr. Lawrence Haward's account of the scheme of loans initiated by the late C. Rutherston's bequest to the Manchester Art Gallery, by Major Longden's informative paper on exhibitions of foreign art, and by a most vigorous address from Dr. G. H. Locke, public librarian of Toronto, on co-operation between libraries and museums. Mr. Eric Maclagan here arrived to explain the kind of help the Victoria and Albert Museum could give to provincial museums, and reopened the discussion on training.

Most of the remaining papers dealt with the educational work of museums. Mr. Harold L. Madison, curator of education at the Cleveland (Ohio) Museum of Natural History, gave a thoughtful and instructive address on the work of his museum in connexion with schools. Miss Bertha Hindshaw related the efforts of the Ancoats Museum, Manchester, to get hold of the 'young visitor' from that poor district. Sir William Furse explained how he had managed to get the numerous small-scale panoramas which add so greatly to the attraction of the Imperial Institute Galleries. Mr. C. A. Siepmann, of the British Broadcasting Corporation, made a suggestive speech on the relations between broadcasting and museums, and this also provoked an animated discussion.

The more technical papers included a demonstration by Mr. W. E. Mayes of making wax models of plants, and notes by Mr. J. Ritchie on the preservation of ancient tempera paintings and on celluloid mounts for insects and herbarium specimens.

After so much time given to papers, the delegates enjoyed a visit to Tarring Cottages and Cissbury Camp, the latter admirably elucidated by Mr. T. Sheppard, and a whole-day excursion to Arundel Castle, Goodwood House, Chichester, Bignor Roman Villa (explained by Mr. S. E. Winbolt), and Petworth House. The remarkably smooth working of the excursions, as of all the other arrangements, was due to the organising capacity of the local secretary, Miss Marian Frost, of the Worthing Museum, aided by the ladies of her staff.

\section{Biology of Norwegian Lakes.}

T BRAARUD, B. Föyn, and H. H. Gran, in a recent paper entitled Biologische Untersuchungen in einigen Seen des östlichen Norwegens AugustSeptember 1927" (Norske Videnskaps-Akademi i Oslo, I. Mathem. Naturvid. Klasse 1928, No. 2), report on several lakes in the east of Norway with regard to the plankton and its environment. The work was carried on in a similar way, but for a longer period, in the Hurdals-See in 1926, and the results published in this same publication (1927). In the Hurdals-See the temperature, oxygen content, hydrogen ion concentration, and distribution of the plankton were investigated at different depths from May to October, the preserved plankton centrifuged and estimated quantitatively side by side with living net-plankton estimated qualitatively, the result showing that most of the species were in largest numbers in summer with a maximum in August-September. Only Dinobryon sertularia formed a maximum in June.

The other lakes, and also the Hurdals-See again, were worked in August and September 1927 with the same methods and apparatus. The plankton of the Hurdals-See was poorer than in 1926, probably because of the very wet summer.

Amongst the nine lakes in question, the Haugatjern was distinctive in having large masses of plankton 
made up of few species occupying the opaque upper layers, a strong oxygen deficit in the depths and below six metres, and definite differences in the hydrogen ion concentration between the upper and deeper layers. Such conditions can only be explained by a strong food stream from land. The plankton production of the Haugatjern is as much as 100 to 1000 times greater per surface unit than any of the other lakes. These lakes are different from one another in several ways, and the amount of plankton varies much in the different lakes. The renewing of the plankton food on which the plankton production depends comes either from the upper layers, by supply from land, or from the depths by vertical circulation. In those lakes where the flowing water in summer must always be comparatively poor in nourishment, the circulation of the food-stuffs for plankton production is more important than the supply from outside. In shallow lakes in summer a daily vertical circulation is possible by the warming of the bottom by radiation, and otherwise in spring and autumn layers are quickly mixed so that maxima are formed of quick-growing planktonic species.

Such distinct maxima at special times of year are to be expected, especially in shallow lakes. In the deeper lakes the circulation is slower and seasonal maxima not so distinct. Thus the differences in the richness of the plankton in those lakes, other than the Haugatjern, can probably be explained best by the fact that the relative richness in the shallower lakes is conditional on a quick eirculation of the foodstuffs present.

The species which take part in the mass production are few. They include Cyanophyceæ, Chlorophyceæ, Flagellata, Dinoflagellata, and Diatomaceæ. The diatoms, especially Asterionella gracillima and Cyanophycer (Anaboena flos aquae and Coelosphoerium Nogelianum), are very quick-growing. Of the dinoflagellates, Ceratium hirundinella is universally pres. ent, reproducing in masses in the Haugatjern.

\section{Agricultural Afghanistan. ${ }^{1}$}

THE Institute of Applied Botany (Leningrad) sent an expedition to Afghanistan in 1924, consisting of the director of the Institute, Prof. N. I. Vavilov, the engineer-agronomist, D. D. Bukinich, and the agronomist, V.N. Lebedev. The principal purposes of the expedition were : (1) To investigate and collect plants cultivated in the country; (2) to ascertain the regularities in the distribution of crops and their varieties over the slopes of the Hindu Kush ; (3) to investigate the technique of local agriculture, the irrigation in particular; (4) to gather information as to the agricultural resources, especially as regards cotton-growing.

The expedition travelled about $6000 \mathrm{~km}$., covering the whole territory of agricultural Afghanistan. The authors divide Afghanistan into six climatic regions : (1) Mountain regions with cold and temperate climate and well-marked differences between the seasons. (a) High mountain regions $2400 \mathrm{~m}$. above sea-level, with 7-9 months of winter. This is the region of spring cereals, chiefly of irrigated crops. The highest altitudes are characterised by a dry desert climate. (b) Regions of temperate climate situated between $1300 \mathrm{~m}$. and $2400 \mathrm{~m}$. above sea-level. This region is chiefly characterised by irrigated winter wheat, and irrigated cultivation generally. (2) The lowland regions below $900 \mathrm{~m}$. (c) Desert regions with small amount of rainfall (less than $250 \mathrm{~mm}$.), very hot summers and cold winters. (d) The region of steppes and foot-hills. The summer is hot, with average temperature above $25^{\circ}$ for the warmest month. This is a region of non-irrigated crops. (e) The lowland of Yalalabad with subtropical, comparatively moist climate. (3) The median zone from $900 \mathrm{~m}$. to $1300 \mathrm{~m}$. ( $f$ ) Desert regions with very small amounts of rainfall and cold winters.

The soils of Afghanistan may be divided into four groups: (1) Heavy loams peculiar to swampy river valleys, chiefly in rice-growing regions; (2) medium loams of the slopes; (3) loess-like loams of the foothills ; (4) the 'irrigation' soils of the oases.

A characteristic feature of Afghanistan is the coexistence of extremely primitive forms of husbandry with rather intensive forms of farming in the oases, which may be observed in the valley of Hari-Rud, especially near Herat. Agriculture of the valley is characterised by extraordinary diversity of crops.

1 Supplement 33rd to the Bulletin of Applied Botany, of Geneties, and Plant-Breeding. Agricultural Afghanistan. (Composed on the Basis of the Data and Materials of the Expedition of the Institute of Applied Botany to Afghanistan.) By Prof. N. Y. Vaviloy and D. D. Bukinich. Pp. iii $+610+x \times x i i+28$ plates. (Leningrad.) In Russian, with summary in English.
The methods of irrigation are thoroughly worked out, cereals are harvested twice a year, and manuring is extensively practised.

The most isolated and unexplored region of Afghanistan is Kafiristan. High up in the thickets of mountain forests, the population practises a sedentary type of agriculture. Fearing the hostility of neighbours, the agricultural population of Kafiristan lives on inaccessible heights. Mills are found everywhere; the plough-where possible. In places some excellently cultivated terraces of crops may be observed. Every foot of soil is utilised.

The study of Afghanistan by the expedition has established the dependence of water sources on meteorological conditions. This is naturally unfavourable to agriculture, which is adapted to the rainfall; thus the increase of acreage under winter crops depends on the rainfall in autumn.

Three principal types of irrigation were observed (1) Source irrigation, (2) kiarese irrigation, and (3) river irrigation. The acreage of irrigated lands in Afghanistan is estimated by the authors as approximately half a million hectares, that of cultivated lands as one and a half million hectares, and the area of 'bohara' as approximately 500,000 hectares. The most wide-spread method of irrigation is with running water. Three peculiarities are noted in the native methods of irrigation : the primitive construction of the main water-carrying canals, and the good condition of small irrigation networks, and the elaborate implements used in preparing fields for irrigation.

The first place in cultivation in Afghanistan is taken by wheat, the second by barley, the third by rice. Then follow the Leguminosæ, and the next place is occupied by cotton. A considerable acreage is under alfalfa and Trifolium resupinatum.

The Hindu Kush dividing Afghanistan determines the general progress of agriculture from the low periphery to the main mountain range, and distinctly shows the regularities in the vertical distribution of the crops over the mountain zones. The authors give a table of the extreme elevation reached by different plants of Afghanistan under conditions of cultivation : hull-less barley, $3400 \mathrm{~m} .-3000 \mathrm{~m}$.; $2500 \mathrm{~m} .-3000 \mathrm{~m}$., hulled barley, peas, spring rye, Ervum Ervilia. This is, on the whole, the zone of spring cereals and of grain Leguminosæ. At $1500 \mathrm{~m} .-2000 \mathrm{~m}$., the majority of cultivated plants appear. This is the zone of maximum diversity of crops and varieties. Grapes may be regarded as the determining plant of the zone. $1000 \mathrm{~m} .-1500 \mathrm{~m}$. is the principal zone of cotton, rice,

No. 3115, VoL. 124] 